\title{
Young People, Sex and Relationships
}

\author{
Lyubov Erofeeva*1 and Dikke Galina ${ }^{2}$ \\ ${ }^{1}$ Director General Regional public organization for Population and Development (RANIR PLUS), Russia \\ ${ }^{2}$ Professor of Obstetrics and Gynaecology, Honored Science and Education Worker, Russia
}

*Corresponding author: Lyubov Erofeeva, Director General Regional public organization for Population and Development (RANIR PLUS), Russia

\section{ARTICLE INFO}

Received: March 20, 2019

Published: 蔧 March 28, 2019

Citation: Lyubov Erofeeva, Dikke Galina. Young People, Sex and Relationships. Biomed J Sci \& Tech Res 16(4)2019. BJSTR. MS.ID.002870.

ABSTRACT

As noted in the UN report, there are 1,2 billion young people aged 15 to 24 years in the world, which equals about $18 \%$ of the world population and $24 \%$ of the working-age population. $85 \%$ of young people live in developing countries where many of them are in extremely vulnerable positions and live under the threat of poverty. Youth constitute 13.2 percent of the population of the Russian Federation and many demographic problems are determined by the relation young people have towards sex and childbearing, family and marriage; by their reproductive and contraceptive behaviors, relationships with authorities, society, and politics, by the features of the reproductive health care system and level of reproductive health services, as well as by gender relationships and reproductive settings. Previously young people were categorized as aged between 14 and 30 years. But recently in most official regions of the Russian Federation there is a tendency to include people up to age 35 in the category of 'young people.'
\end{abstract}

Aim of investigation: To study the contemporary features of reproductive behavior and reproductive choices of young women and men in contemporary Russia and to determine the impact of societal transformations on them.

\section{Materials and Methods}

An integrative analysis of the problems facing Russian youth under contemporary social transformations has been carried out using data from various sources, reflecting relations between young people and state authorities, as well as with political, societal, and non-governmental organizations. Furthermore, young people's gender relations, information awareness, knowledge levels, sexual behaviors, and reproductive choices have been studied using original survey data. Students at the Moscow State Pedagogical University were selected as a sample for this part of our investigation. The number of respondents was 585 persons aged 16-19, including 402 (68.7\%) females and 183 (31.3\%) males. The mean age was $16.0 \pm 1.1$ years for females and $17.6 \pm 1.5$ years for males. Statistical analysis of the survey data was performed using standard application of Microsoft Office Excel for Windows XP. Basic statistical parameters were calculated with the use of the specialized statistical software package Statistica 6.0. We used a descriptive statistic method to calculate the mean, dispersion and 95\% confidence interval. The significance of the difference between the two mean values was estimated using a t-test. To compare values we used a confidence interval within which $95 \%$ of all values were presented-sample mean + /- three standard deviations (rule of three $\sigma$ ). To compare two qualitative indicators we used the fisher test (chi-squared) and an estimate of its significance at $\mathrm{p}<0.05$.

\section{Results}

The crisis-ridden political, social, and economic conditions of modern society significantly impact youth sexual relationships, reproductive plans. The comprehensive analysis of the problems youth face amidst broad social transformations [1,2] has revealed escalating inequalities in income distribution and financial conditions, a lack of access to public resources, widespread unemployment, and growing marginalization. The problems youth face are compounded by shortcomings in education and health care services, and an increase of social alienation. An analysis of contemporary Russian youth's identification with various social communities reveals that more than $2 / 3$ expressed a commitment 
to alternative sub-cultures, a correlate of young people's lack of trust in larger social and state organizations. At a broader scale, the most prominent identity among Russian youth was based on generation. About half of young people surveyed did not trust the executive powers or legislative authorities; their confidence in lawenforcement agencies is inconsistent, demonstrating growing legal nihilism in youth worldviews.

The results of a poll by the Public Opinion Foundation [3] suggest that young people have clear, pragmatic attitudes, intend to achieve material well-being and career success, which are interrelated with the opportunity of acquiring good professional education [4]. A key characteristic of contemporary youth is a general trend in shifting attitudes towards life away from social ('collectivist') goals towards individual ones. Material well-being is currently valued much more than freedom, and youth prioritize the importance of salaries and compensation over the importance of interesting work. Among the social problems that most trouble young people presently are crime, increasing prices and inflation, extensive corruption, increasing income inequality and social inequality, including stratification between rich and poor, ecological problems, and civic passivity. One of the most common personal problems concerning youth is the interrelated issue of material well-being and health, although healthy lifestyle trends remain uncommon [5]. The dominant values among contemporary youth are money, education and a profession, a business career, and the opportunity to enjoy life (Table 1).

Table 1: Distribution of main values of young people [3].

\begin{tabular}{|c|c|c|}
\hline No. & Values & Priorities \\
\hline 1 & Money & $35,3 \%$ \\
\hline 2 & Education and profession & $31,4 \%$ \\
\hline 3 & To get more pleasure from life & $20,7 \%$ \\
\hline 4 & Business career & $19,6 \%$ \\
\hline 5 & Love & $11,6 \%$ \\
\hline 6 & Sex & $8,3 \%$ \\
\hline 7 & Peace (not war) & $7,8 \%$ \\
\hline 8 & Family & $7,5 \%$ \\
\hline 9 & Actions on behalf of Russia's future & $4,5 \%$ \\
\hline 10 & Ideals, belief and religion & $2,7 \%$ \\
\hline
\end{tabular}

Since 2001, the All-Russian Association of NGOs, "Union of Youth Organizations of the Russian Federation" (SOIUZMOL), has been engaging in a variety of activities to provide comprehensive support for non-government youth organizations throughout the country. However, besides youth groups in a number of regions within the Russian Association for Population and Development (RAPD, or RANiR) which are active in the field of reproductive health and rights in return for some minimal compensation, there are no young volunteers.

Informal groups of organized youth are an important part of a democratic, pluralistic civil society. Contrary to older generations which may be relatively conservative and close-minded, young people more often courageously pursue innovative lifestyles and undertake groundbreaking life strategies, thereby producing some of the most cutting-edge sources of political and social transformation. Due to their informal organizational structures, youth often establish confrontational stances vis-à-vis older generations and challenge the dominance of existing authorities [6]. The Russian state has established a national, political strategy for addressing the population's reproductive health care. However, the absolute majority of respondents believes that a healthy life style cannot be engineered from above but results from people's own personal efforts, and that Russia's transformation into a society that embraces healthy life styles is far in the future (65.9\%) [7]. Characteristics of gender relationships and reproductive behaviors among youth. Our data reveal that over $67 \%$ of girls and boys have had some sexual experience by the age of 18 . The feature characteristic of both sexes was an irregular sex life with intervals of activity between one and six months and with intercourse frequency up to 3-4 times per week. $56.3 \%$ of respondents were not planning to establish a family during the coming year.

Among female respondents, sexual debut before 14 years old did not reach $1 \%$, whereas among boys of this $6.6 \%$ of respondents stated that they had already had sexual experience ( $p<0,002) .16 .4 \%$ of girls and $28.1 \%(p<0,01)$ of boys became sexually active before the age of 16 . The maximum frequency of sexual debuts among girls occurred between the ages of 16-18 (62,9\%), forming a "plateau" in the distribution of this frequency by years at a range between $20 \%$ and $21 \%$. In boys the "peak" time of becoming sexually active was age $16(30.4 \%)$, although the maximum frequency of sexual debuts was observed between ages 15 and 17 inclusively $(57,1 \%)$. The mean age of sexual debut among the interviewed girls was $17.0 \pm 1.7$ years, and among boys $-16.0 \pm 1.8$ years. The early onset of sexual activity coincides with the establishment of premarital partnerships, and several noteworthy changes in these relationships distinguish contemporary cohorts from earlier generations. In comparison with adolescents in the 1970-1980s, who aimed to undertake childbearing within marriage and become "adolescent mothers", modern young people postpone weddings (on average, the acceptable age for marriage was $23.1 \pm 0.8$ years) and prefer new forms of partnership such as civil unions (44.3\%). Even those adolescents who bore children did not choose marriage as a form of family relations: only a quarter $(25.7 \%)$ of women having children was officially married at the time they gave birth, and one third of them had never been married. For girls who were officially married, the mean age at the time of the wedding was $17.0 \pm 0.3$ years.

Results regarding the use of contraceptives demonstrate that at the last sexual intercourse, girls used contraceptives significantly more often $(85.3 \%)$ than boys $(74.1 \%, \mathrm{p}<0.01)$. The number of girls using Combined Oral Contraceptives(COC) increased from $6.5 \%$ to $18.7 \%(\mathrm{p}<0.001)$ over time as they sexual activity 
became more frequent (as measured between the first and the last sexual intercourse), while the proportion of girls using condoms significantly decreased from $78.8 \%$ to $68.2 \%(\mathrm{p}<0,05)$. In spite of the irregularity and unpredictability of sexual activity among youth, there were only exceptional cases of the use of emergency contraception $(0,7 \%)$. The number of persons using a combination of several contraceptive methods/drugs (condom+COC) increased from $7.8 \%$ to $13.4 \%(\mathrm{p}<0.05)$, significantly correlating with the time since the onset of sexual activity. Among adolescent girls, $6.2 \%$ reported parity, $91 \%$ stated they had never been pregnant, and $2.7 \%$ gave no answer. At the time of first pregnancy, $52 \%$ of female respondents had never been married, $28 \%$ were currently officially married, $12 \%$ were divorced, and $8 \%$ were in a civil union (cohabiting). For $28 \%$ of the adolescents participating in survey and having parity, the pregnancy was wanted, $20 \%$ noted that it was wanted more than unwanted, and in $44 \%$ of cases, it was unwanted or unwanted more than wanted.

In general, outcomes of the first pregnancy in the studied cohort of young women were associated with an abortion (64.9\%), whereas less than one third (28.4\%) of them preferred to give birth. Thus, in this study, the rate of abortions to births was 2.3:1.0, which supercedes the rates for women in all age groups-0.7:1.0 (according to data of the Ministry of Health and Social Development of the Russian Federation, 2010). The data obtained from our study show that in about half of all cases of pregnancy (48.0\%), boys had proposed marriage to their girlfriends, whereas each fifth partner (about 20\%) had urged an abortion. The overriding reason for pregnancy termination (the question concerning reasons offered several possible answers) was an unwillingness to have children at the present time (88.9\%). In $44.4 \%$ of cases, the abortion was undertaken with the mutual consent of both partners, and the same number of respondents indicated reasons of an economic character for the abortion (such as a lack of money/means for raising a child and homelessness). In 55\% of cases of pregnancy termination, the reason was designated as the girl's immaturity, such as being unprepared for motherhood, an unwillingness to have a child with this partner, as well as an abortion due to parental decision. These reasons reflect a low level of contraceptive behavior and lowlevel of responsibility in the reproductive behavior of the female respondents.

Adolescents views about reproductive reveal their desire to have no more than two children in the future (1.9 on average). The survey found youth are dissatisfied with the amount and quality of information they have, despite their high need for it. The topics adolescents found most interesting involve life styles conducive to reproductive health (44\%) and pregnancy prevention methods (42\%). Issues associated with sexually transmitted infections appear to be less interesting to them (36\%). Despite young people's high demand for reliable information and adequate medical and reproductive health services, adolescents express strong resistance towards using health care institutions (women's outpatient clinics,
STIs clinics, and general outpatient clinics) and only seek care from them in the most urgent cases.

\section{Discussions}

Our investigation confirms the conclusions of the Reproductive Health and Youth Rights in Russian Federation project (2000-2002) [8], which found that efforts to maintain the reproductive health potential of contemporary adolescents were inadequate due to the lack of formal sexual education programs that address issues of reproductive health and safe sexual behavior (before adolescents become sexually active), as well as due to the lack of multi-disciplinary interactions between the healthcare and education systems, the lack of a national system of accessible and user-friendly medical, health care consulting and information services for adolescents, and medical professionals' inadequate skills in providing confidential and friendly obstetric-gynecologic services for adolescents. All of the above mentioned issues suggest a systematic risk that existing problems will become aggravated. Our review of the scientific literature reveals that contemporary youth have a variety of problems related to social and economic issues, access to quality health services, as well as with changing value systems, all of which have an impact on gender relationships, reproductive behaviors and intentions. Youth behaviors are characterized by an earlier onset of sexual activity, non-marital relationships, the postponement of childbearing, intentions to have precious few children, and patterns of poor contraceptive use, which in general reflect tendencies common across the Russian population.

Beginning in the 1990s, the number of couples living in a civil union increased to three million, resulting in a substantial increase in the number of children born out of wedlock and, in cases when the relationship ends (more 30\%), a greater number of single mothers left without support from their children's father. Young people aged 18-25 more often express the desire to have only one child $(14 \%)$ as compared to older respondents (6-9\%), and vice versa, they less frequently express a desire to have three or more children (25\% and 34-39\%, respectively) [9]. No more than a quarter of women of reproductive age $(23 \%)$ use modern contraceptive methods, whereas the contraceptive demands of $30-40 \%$ of women remain unmet-and the resulting unplanned pregnancies get legally terminated at early stages (28.2 cases per 1000 fertile women (2010)). The demographic situation in Russia is characterized by complex and controversial processes in population development. The Russian Federation is home to the $7^{\text {th }}$ largest population worldwide after China, India, USA, Indonesia, Brazil and Pakistan [1]. At the start of the $21^{\text {st }}$ century the conditions of Russian society favored persistent depopulation and indeed the country had one of the highest global rates of natural population decline.

Concerned about these trends, Russian government authorities have shown growing attention to demographic and social problems and have redirected national policies to provide support for motherhood and childhood. National programs targeted to 
stabilizing and improving the demographic situation have been approved by government bodies; at present, a financing mechanism for programs targeted to supporting motherhood and childhood has been developed and implemented in Russia. National demographic policy in the field of raising the birth rate and strengthening the family [10] includes the following tasks: creating preconditions for an increase of the birth rate through a gradual transition from families predominantly having an only child to having two children and more; a comprehensive approach to strengthening the institution of the family as the form for the most rational vital activities and socialization of people; establishing conditions for youth self-realization; and a social safety and financial reward for responsible parenthood. However, expenditure levels for familysupportive measures (the share of expenses for the family, mother and child allowances in \% of GDP) were decreasing and, between 2003-2006, were 8-10 times less than analogous expenditures in European countries, where they range on average between 2 and 2.5\% (in France, for example, these expenditures reach about 4\%).

In spite of the apparent magnitude of measures approved in 2007-2010, they are not enough effective to provide opportunities for young families to take freer and more responsible decisions regarding child bearing. The analysis has shown that even after doubling up expenditures for family support in 2007 compared to 2006 and indexing it to the rate of inflation in 2008-2010, this parameter (in \% relative to GDP), remains at a level that is $1.5-2$ times less than it was in 1995 in Russia and 4-5 times less than it was in 1990-1991. There is still no discernible impact of these allowances on family incomes. The assistance provided for families with dependent children at present is apparently insufficient either for spurring couples to give birth to a second or third child, or more generally for stimulating the birthrate, changing social value systems, or increasing the prestige of a large family with several children. Families with dependent children face high risks of poverty as a result of low wages and low levels of state financial allowances for mother and child. For most young families, child bearing results in the dramatic worsening of living standards. The number of children has become one of the main factors associated with poverty.

In 1994 at the International Conference on Population and Development convened under the auspices of the United Nations (ICPD UN), the governments of states members agreed to meet re-

ISSN: 2574-1241

DOI: 10.26717/BJSTR.2019.16.002870

Lyubov Erofeeva. Biomed J Sci \& Tech Res

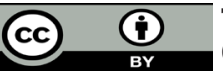

This work is licensed under Creative

Commons Attribution 4.0 License

Submission Link: https://biomedres.us/submit-manuscript.php quirements of adolescents and young people in information, counseling and high-quality healthcare services "as a way, which encourages adolescents and young peoples to continue their education, to develop their potential, and prevent early marriage as well as a high risk of child bearing" [11]. ICPD UN and the Fourth World Conference on Women (Beijing, 1995) define these not only as young people's demands, but also as their rights $[11,12]$. The insufficient information and lack of awareness that Russian adolescents have regarding issues of reproductive health care may be overcome by introducing special programs in educational institutions, as well as by modernizing healthcare institutions' work and orienting it to be more user-friendly towards adolescents' needs.

\section{Conclusion}

a) Russia's current socio-economic status greatly impacts the life priorities that young people hold, which are generally directed towards improving their material well-being rather than establishing a family and childbearing.

b) In general, gender relationships are limited to satisfying sexual demands, which occurs in the context of poorly developed contraceptive behaviors and insufficient sexual education.

\section{References}

1. (2007) World Youth Report 2007: Young People's Transition to Adulthood - Progress and Challenges, pp. 348.

2. Tarzan VN (2010) Official youth policy in modern Russia. Political investigations (POLIS) 3: 156-160.

3. Youth Survey (2002) Principles and values of young people, p. 18-23.

4. Karpukhin OI (2000) Young people in Russia: features of socialization and self-definition. Sociological investigations 3: 126 .

5. Pitirim Sorokin Foundation (2007) Values in modern Russia: Results of the expert investigation.

6. Potseluiev SP (2006) Informal groups of young people.

7. (2004) Youth situation in education system of Russia. Moscow, Rosobrazovanie, University of People Friendship.

8. (2000-2002) Reproductive health and youth rights in the Russian Federation, UNFPA

9. Vovk E (2007) A number of children in family: settings and reproductive behavior. Social Reality.

10. (2007) Demographic Policy Concept in the Russian Federation for the Period through to 2025.

11. (1995) Report of the World Summit on Social Development.

12. (1995) Report of the Fourth World Conference on Women, China. 